\title{
Halbringe \\ Algebraische Theorie und Anwendungen in der Informatik Udo Hebisch und Hanns Joachim Weinert
}

Teubner Studienbücher, 1993, pp. vi+361. DM 42.80

ISBN 3-519-02091-2

\section{Richard Wiegandt}

Communicated by Boris M. Schein

When this review was published in the last issue of Semigroup Forum [1], much of the information about the book was inadvertently omitted, including the authors' names and the information about the publisher. The error was the fault of the Journal Secretary, who regrets the omission of the information.

\section{References}

[1] R. Wiegandt, Review of "Halbringe: Algebraische Theorie und Anwendungen in der Informatik", Semigroup Forum 52 (1996), 247-248. 